\title{
Gender differences in learning mathematics with Digital Games
}

\section{K. Pulasthi Dhananjaya Gunawardhana}

Senior Lecturer, Department of Information \& Communication Technology, Faculty of Technology, University of Sri Jayewardenapura, Sri Lanka

\begin{abstract}
Digital games are the latest learning technologies which need to be confirm the possibility for applying to both gender equally. Through this paper we are going to discuss about the gender difference on game and how possible apply digital games for learning mathematics with the gender differences. We have reviewed applicable research methods to gain fruitful results on gender aspects. In here we have discuss about the gender-based variety in educational games, developing proper game model, and research and gather evidences on gender aspects and possibility of using digital games for learning mathematics. Through this paper we are going to reveal that boys are more likely to play digital game than girls. And also this paper highlights the differences which type of games boys and girls would like to play and we have describe the reason for choosing games on gender based.
\end{abstract}

Keywords

Gender Differences, Digital Games, Educational Digital Games, Gamification, Game Design, Gender Aspects

Article Received: 10 August 2020, Revised: 25 October 2020, Accepted: 18 November 2020

\section{Introduction}

In modern world children are influence with latest technology. Most of them used to spend their leisure time playing with digital game and etc. Current development in technology certainly effect for education as well. As famous researcher Prensky talk about through his paper, students in modern world are not compatible with educational system which running currently. Therefore, with the help of technology teaching and learning methods should develop for the current needs [1]. Most of the young crowd are like to use game with VR (Virtual Reality). The gaming technology which interact education may helpful to change the learning techniques. Engagement and motivation are key benefits of using digital games, but it is yet not enough to count down for educational purposes. There is a relationship amid playing and the mathematical thinking of a student. Understanding this is not a new singularity. A researcher named Van Oers once said through his paper, "by playing digital games make the opportunity to practice the selected lessons and escalate the skills" [2]. When developing the technologies, the connection between the visual and spatial impetus extended the chance of involve with digital games. Most of the modern digital games make an effect for students to engage with maths.

As to the recent studies indicates that $90 \%$ male game players belong to age group of 8 to 18 . And also leading game developing company have spent nearly 8 billion US dollars developing digital game for the past couple of years [3]. Digital games, which has active nature, productive and motivational opportunities are efficacious technology, whose likely of being applied for learning has been progressively discussed since the 2000s. The feature that will be measured through this report could be varied with regards to students regarding their approach and acceptance towards digital game based learning, exclusively ultimate gender differences. Through this paper we are going to discuss about characteristics of the gender towards digital games, based on that, we are going to general discuss on gender based adoption, Gender Stereotype on games, gender-sensitive approach of designing games for educational purposes. Then we are going to discuss based on gender difference, student's engagement on digital games and deliberates the effect on learning mathematics.

\section{Gender Differences On Digital Games}

In general, most of the digital games available on the market are played by boys rather than by girls. The general consensus regarding digital games is that boys tend to play these digital games for longer periods than girls do, and that males are more likely to use digital games than females. Previous research has confirmed that most girls are likely to engage in role- playing games rather than action and fighting games. Even as the general popularity of digital games continues to rise, the majority of people who play them are still males. Boys having a higher need for achievement when they playing digital games. Once two researchers name Boyle and Conolly mention through their paper that, this need for achievement is linked with challenge [4]. Hartmann and Klimmt (2006) highlight the reason for this gender gap in playing digital games as being linked to personal traits in each gender. Apparently, they said that effectiveness on trait can be clarified by three gears. These are; motivation for success, the necessity to success, and finally, self-efficacy. These three factors are more important for boys rather than girls [5]. Boys who play games are expecting more challengeable environments than girls.

Lucas and Sherry (2004) discovered that the game player is looking for a game that will evoke various fresh and powerful feelings and experiences, and will allows the player to take risks. Digital game developers are therefore always trying to evoke these extraordinary feelings in its players, as this desire for these feelings is the key motivation for playing digital games. The researchers also confirmed that this desire is more significant for boys than for girls. Additionally, they have found that girls are more likely to 
involve themselves with non-violent digital games [6]. Agosto (2004) mentions in his article that girls characteristically show pro-social patterns and enjoy playing digital games that involve interaction with society and human relationships. Most digital games provide a chance to interact with society and with other people rather than being action-oriented, but when these characteristics of social interaction are absent in the game, girls get bored and discontinue playing the games [7]. Girls are always good on obviously express their preference on something, so as for games as well. Most of the researchers mention that they value digital games which has meaningful dialogues and good interaction with it users. Frequently, digital games deliver opportunities for social interaction. Lack of social interaction in modern digital game count as the reason for girls not like to involve with games [5].

Because boys and girls are usually different in many ways, the type of digital games they prefer to play are also different. The motivation factor for play digital games also differ between genders. As previously discussed, these preferences are due to different interests and desires, which have been acquired through socialization. Even though boys generally select action, adventure, and simulation games with violent content, girls tend to prefer puzzles, board games, and role playing games. When selecting digital games, boys generally select games that have an element of competition and winning, but girls predominantly select games for their storylines and for the characters in that particular game. The evidence that we have gathered suggests that girls prefer games that are unhurried, and like to select a colourful, slow-moving graphic user interface (GUI). Because of this tendency, we chose a role-playing game for girls for our research in order to determine the possibility of using digital games as an educational tool.

When discussing about best-selling digital games we have found that only few of the character are female, and major part of the roles are rather spectators than active game players. As Graner highlighted from his paper, that stereotypes and archaic models are useful to represent girl game characters. Most of these girl character are highlights with weak and need to be secure by strong boy or male character and these boy/male character design to elaborate female sexuality [8]. This is a falsification can be seen in most games and this could be major reason for girls not interest in playing digital games. But when we look at digital games made for girls, female characters express strong preferences when compare to games play by boys. Gender differences also affect to game avatars as well. Most of the boys who play games select male avatars, while girls select female avatars. As to our study we found that boys who play games are always looking powerful avatars, while girls as usual selecting fashionable and beautiful avatars.

\section{Gender Aspect On Digital Games}

Based on Knowledge Space Theory, Kickmeier et al refine the background of the educational digital gaming system to escalate the children's skills and gender differences and the usage of the fundamentals [9]. We are expecting that given concept requirement a conjecture connection between these elements can be proven which captures the experience how to consequent through a research and empirical studies could be count as individual factors. Not that all, Kickmeier et al introduce a prototype that integrating individual factors manipulating student's selection on educational digital games and it has confirmed gender differences in order to model a structure for gender differences in connection between the individual factors as it is link with adaptation of an educational digital gaming system. Use of this methodology prove that there is a possibility for students to states that mixtures of individual aspects could be helping to reduce to an expressed sequence by creating essential expectations based on current research evidences. As we discuss about gender aspect in previously, it covers the many features about the digital games on gender differences which have been verify about key concepts and characteristics. These key hypotheses mention characteristic of the gender differences and relatively clarify the gender gap in the different digital game characteristics.

These different selections of the digital games by girls and boys, can be clarified as gender differences in competition placement and interaction preferences. These factors could be the reason for encouragement to involve with digital games. This will be helpful to turn into manipulating the selection of the type of digital game and the usage. Duration of playing digital games also reason for effective for uplifting skills of a students. We have developed this framework further to do our research which will be discuss in next topic. When we reviewing our research results in which we done, web based educational games and elearning systems has shown that girls are always prefer vibrant background design which use attractive colours, while boys prefer a complex design and they are attracted for more realistic graphical elements and interactive features. There is one reasonable explanation for the judgement for the gender differences using for educational digital games. In 2003 two researchers name Dickhäuser and Stiensmeier said that the features in digital games are the reason for its player's success or failure, as it is meticulously identify and verify the gender differences. Boys are habitually like to explain their success and how they did it. But girls are incline to point the cause of failure more likely than boy. These features preferences are referred to the selfefficacy principles that can be verified to be higher for boys in the background of digital games [12]. Two researchers' name Ziegler and Stoeger once mention in their paper that, a flawed ascription manner could seems to be in other areas as well and it could be linked with unfitted performance that will sooner or later lead to prevention [13]. Apparently for that the most of the variables could be modified by assisting in clarifying the procedural arrangements in digital games. With regards our framework, reason for playing digital games could be count as escalating computer literacy, but the assumption of playing digital game successfully can be count on self-efficacy. These assumptions for playing digital games would be a liable aspects for selection to play an educational digital games.

\section{Digital Game For Mathematics}

\subsection{Standards for the games.}

In here we are going to discuss the required guidelines for designing a proper digital game for the purpose of teaching 
mathematics. In our previous discussions we have elaborated on the factors of gender aspect why the young students like to involve with digital games. Digital games can be applied as a very effective learning method that can be introduced to teach certain subjects. Digital games help to sharpen the skills such as; problem-solving, exploration, collaborating and working as a team as well as providing support to enhance the knowledge and skills that can be transferred depending on the situation and be effective in an educational context. There are two key principles which need to be attached to design a proper educational digital game. These key principles are described as below.

Engagement: - Key factors which cause to engage in digital game as we found earlier are the user goals in each stage weather individual or group, they play a particular digital game and feedback they get. Feedback is necessary in order to identify the strength and weakness and to score better at next level. The digital game, we are planning going to design should be easy to deal within the first level and it should be made difficult at the next levels. These should be more new features added to the game compared to previous level. The challenges given should match with the student's age group and subject as well. This will enable the players to achieve initial goals and see themselves the improvement of the performance. This could be combined with the controlling factor of the educational gaming are of the learning environment.

Active Learning: - When we plan to design a proper digital game which is actively used for an educational purpose the goals of such an exercise should be very clear to it users. It should also provide for teamwork. The game which we develop is based on logical thinking and problem-solving. By solving mathematical problems either by the player himself /herself or as a team it helps to explore the options and solving problems by discussing with each other. This game should help to refine the logical thinking related to mathematical sums as well as practise mathematics as learned in a school. Since these game enables the players to tryout their guesses if they are not sure of the answer and they can get the correct answer by changing a few guesses. If a student plays in a team they could discuss and select the correct answer. This particular game has been design to give opportunity to practice and gain working skills. This game has been designed learn while playing, which is easy to increase the learning skills and go for higher grade.

\subsection{Game Elements}

To develop better educational game, we need to identify the elements of the games. Game element can divide into 3 main parts. They are Dynamic, Mechanism and Components. In 2012 two researchers named Werbach \& Hunter illustrated the hierarchy of the Game elements through a pyramid which is shown in figure 1 .

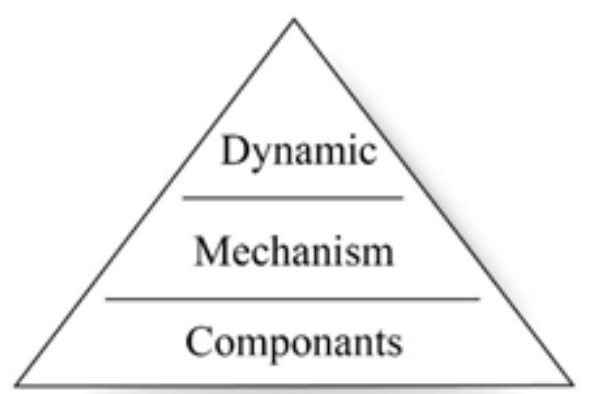

Figure 1: hierarchy of the Game elements [14]

Dynamics - Dynamic defines the abstract of the educational game system. Dynamic connect three important layers, especially for educational games. By describing these three layers we can identify how important these layers have become when building a proper educational digital game.

Emotion - This is the element in which the users/players show their feedback toward to the game they have played. When they complete the given task usually they feel happy. At the same time when the game release new features or allow the player to unlock new stage, etc. So player feel enthusiastic and get required motivation to play the game further. As to our view educational games never let the students to feel frustrated. It makes them to feel happy and motivate them to learn while playing the game. It also helps to connect the student and the teacher within the scope of the school curriculum.

Relationship - This is the factor that shows us that two or more thing connect and function together. Otherwise this cannot be termed as a successful game. Relationship plays the main role within the dynamic element which attracts the users to the game. In an educational gaming system, it gives chances to have possible answers to given questions to win the game. This makes game users to play as a team to achieve their goals specified in the game. This could be an attributed as a valid reason for game players to interact with the system.

Boundary - There should be a limit to playing games. If there is no limit, these children/students may get addicted to such games. There should be appropriate guidance for the game players. These boundaries play different roles depends on the nature of the game. This can be done by the system when developing the game, by adding monitoring and controlling panel for the teacher/parent. Furthermore there are few more roles that could apply as a mediator or a normal member.

Mechanism: - This can be termed as the second element of game designing. Werbach and Hunter once said, "basic processes that drive the action forward and generate player engagement" [14]. There are four main elements we consider under Game Mechanism. They are, Points, Badges, Rewards and Lead board.

Points - These are the key currency of the game. To earn points, a player has to work hard and achieve the given task. Point allocation is a great method to illustrate players' progress and capacity compared to other players. This will help the positioning of a player in the ranking order. The point system is a highly motivational one for the players and it is very effective as well. Based on the collection of points, 
it is easy for teachers to identify the weak students and the area in which the weakness is evident.

Badges - In educational digital games, the badging method is adopted to highlight the player's competencies. This will enable other players to recognise his or her competencies and talents for a particular game. In educational digital games, players are able to earn their badges by playing the game with their achievements. Badges symbolise the player's profile and achievement records and they are the elements responsible for maintaining the challenges in a particular game. Badges can be a source of help to the game users by giving necessary feedback which will be a source of identifying the progress of a user.

Rewards - This is another method of encouraging the player to spend more time with the game. Once the player successfully completes the given task or the particular stage, the player will be rewarded. According to educational digital game theory brought forward by Zichermann and Cunningham, these rewards must be non-monetary and the player is not given points for his or her success either [15]. This will provide more opportunities and chances of getting rewards by the successful player/student. Once the mission is completed and the player gets satisfied, they will be happy and enthusiastic to complete other the missions. Game players are naturally motivated by the action alone itself.

Lead board -Through this feature, the progress made by each player in a particular game and their achievements are shown. The collection of points and badges will be announced here. By collecting points and badges and by displaying them on a lead board, each player by themself could improve their ranking as well as getting recognised by other players. It will also help the player or team to adopt new techniques to get on top of the lead board. When the player is found to be in a lower position of the lead board, necessary measures could be adopted to encourage the player to advance on the lead board and improve their ranking.

Components: - The final part of the game element is the components. There should be relevant components to build a proper educational digital game. In this section we will give a brief description on the impotence of components. Levels, Privileges, and Teamwork are the key components which should be within a proper educational game.

Levels - This help the game players to reach the given target step by step without getting bored of the game. In order to reach to higher levels the game players need to gain points which are indicated in the game itself. These points motivates the player to level up in a game. Game players who socialize with other players try to find out more tactics when they are in the same level. When the game player level-up they can unlock new features and this will help them to motivate to explore further into the game.

Privileges - This is similar to "rewards" which we have discussed earlier under the subject of mechanism. Privileges help the players to avoid unnecessary features and help to unlock the levels as well as new abilities which drives the game players towards its approach. Digital games rather used to be designed with minimum number of obstacles in order to gain the desired abilities of the player. This is why we should give the privileges to a game player which encourage them to play well. The main idea of providing a component like privileges is to motivate the player as well as to minimise the frustration of player.

Teamwork - Teamwork is an important aspect which a students have to learn from the school. Finding an answer for a difficult question is much easier when they try as a team rather trying it on your own. Therefore the game player needs to co-operate with each other as team in order to succeed in a game. Apart from that connectivity with other team members while playing the game is important to have a successful outcome. It will also help to develop new friendships and contacts as well.

\section{Discussion}

Following the above discussed guidelines we have developed the educational digital game for practising mathematics. In accordance with to the discussed guidelines this game production framework contained the following phases: Analysis, Design, Development, Implementation, and finally the Evaluation. Therefore, we developed this model game carefully and work thorough as to the requirements analysis, in order to developed proper game. We request from teacher to observe the educational process and the students' performance during classes time. For this research we took 120 students from 3 different countries, numbering 60 students from UK, 36 from Australia and 24 from Sri Lanka. These student group is mix of girls and boys in each country.

Before start the research we gave questionnaire to find-out what is the most desired gaming typing of the student based on gender. Then we have found most of the boy like for racing game and role play game for girls. So we have selected two games according to gender that contain teaching element for teaching general mathematics to grade 7 students. This exercise took into account several factors: the students' level of memorisation, learning, logical thinking, problem solving, creativity, socializing (which represents different analytical levels), gender differences, and the ability for us to receive their feedback on possible improvements of them. Based on these factors, we will discuss the effectiveness of using digital game as an educational tool. The most relevant method for testing effectiveness is to evaluate the method's results (in this case, student's skills scores) in comparison with the results of the traditional method. The following charts show the head count of the students in each country based on gender.

\begin{tabular}{|c|c|c|c|}
\hline \multicolumn{4}{|l|}{40} \\
\hline \multicolumn{4}{|l|}{30} \\
\hline \multicolumn{4}{|l|}{20} \\
\hline \multicolumn{4}{|l|}{10} \\
\hline 0 & UK & Australia & Sri Lanka \\
\hline Girls & 28 & 14 & 9 \\
\hline Boy & 32 & 22 & 15 \\
\hline \multicolumn{4}{|c|}{ Girls Boy } \\
\hline
\end{tabular}


Table -1: Students Divide by Gender

We have interviewed teachers from the selected schools to find out the progress of the students, after they play digital games. We have given two types of game grouping them based on gender. For the boys we gave a racing game and for the girls a role play game. This Research concentrated on the subject of finding out possibility of using educational digital games as a teaching tool for mathematics. We have requested from the class teachers to monitor their progress and mark them accordingly.

We request from the class teachers to monitor their progress and mark them accordingly. As to the table below which given the result of the research, it has been a successful exercise. We tested these children before and after playing game. We have given student to small test after usual in class activities (without involving computer games). Then with the help of the class teachers, we let these kids to play and practise mathematics. This process took around $3-4$ months. Then we provide small test to check their progress. All the question papers which we were distributed, prepared by according to the syllabus and these papers were marked by the class teachers in each country. We let them play this game only when mathematic class session which men around 1 hour per day for a week ( 5 days). Table 1 indicates the result of the research. As the four teachers in the three different countries which we have mentioned said, that the student's "Problem Solving" skill was level up as we expected. The next highest rate is the "Critical Thinking" factor. This research also reveals that students show progress in mathematical subjects when student get involve in educational digital games. When the student practice mathematics using these digital games again and again, it help them to practice to solve mathematical problems in a more logical manner and make them to do it easy. According to our survey digital games for secondary school students are constant in showing the popularity among them for involved in educational digital games. The feeling of excitement when playing a games make them to go for the completion of the game even it is complex nature. There was also a high degree of acceptance amongst students that educational digital games could be meaningfully applied for learning purposes. Table 1 below explain this scenario.

\begin{tabular}{|c|c|c|c|c|c|c|c|c|c|c|}
\hline \multicolumn{11}{|c|}{ Before Playing Games } \\
\hline \multirow[t]{2}{*}{ Student } & \multicolumn{2}{|c|}{$\begin{array}{l}\text { Problem } \\
\text { Solving }\end{array}$} & \multicolumn{2}{|c|}{$\begin{array}{l}\text { Critical } \\
\text { thinking }\end{array}$} & \multicolumn{2}{|c|}{ Teamwork } & \multicolumn{2}{|c|}{$\begin{array}{l}\text { Analyse and } \\
\text { Classifying }\end{array}$} & \multicolumn{2}{|c|}{ Creativity } \\
\hline & Boys & Girls & Boys & Girls & Boys & Girls & Boys & Girls & Boys & Girls \\
\hline UK & $54 \%$ & $52 \%$ & $45 \%$ & $46 \%$ & $49 \%$ & $45 \%$ & $40 \%$ & $41 \%$ & $40 \%$ & $42 \%$ \\
\hline Australia & $64 \%$ & $62 \%$ & $56 \%$ & $55 \%$ & $57 \%$ & $55 \%$ & $45 \%$ & $44 \%$ & $50 \%$ & $52 \%$ \\
\hline SL & $70 \%$ & $71 \%$ & $44 \%$ & $45 \%$ & $54 \%$ & $50 \%$ & $42 \%$ & $42 \%$ & $54 \%$ & $56 \%$ \\
\hline \multicolumn{11}{|c|}{ After Playing Game } \\
\hline \multirow[t]{2}{*}{ Student } & \multicolumn{2}{|c|}{$\begin{array}{l}\text { Problem } \\
\text { Solving }\end{array}$} & \multicolumn{2}{|c|}{$\begin{array}{l}\text { Critical } \\
\text { thinking }\end{array}$} & \multicolumn{2}{|c|}{ Teamwork } & \multicolumn{2}{|c|}{$\begin{array}{l}\text { Analyse and } \\
\text { Classifying }\end{array}$} & \multicolumn{2}{|c|}{ Creativity } \\
\hline & Boys & Girls & Boys & Girls & Boys & Girls & Boys & Girls & Boys & Girls \\
\hline UK & $81 \%$ & $78 \%$ & $62 \%$ & $63 \%$ & $62 \%$ & $58 \%$ & $54 \%$ & $55 \%$ & $51 \%$ & $53 \%$ \\
\hline Australia & $84 \%$ & $85 \%$ & $80 \%$ & $82 \%$ & $68 \%$ & $65 \%$ & $65 \%$ & $64 \%$ & $57 \%$ & $59 \%$ \\
\hline SL & $82 \%$ & $83 \%$ & $65 \%$ & $66 \%$ & $64 \%$ & $60 \%$ & $68 \%$ & $67 \%$ & $60 \%$ & $62 \%$ \\
\hline
\end{tabular}

Table 2: Before and After Playing Games

As to the result shown in table 1 we can see how effective is that digital games are. When boys played these games to practice mathematics they showed increase of their performance. These results also same to girls as well. Since these kids have spent certain time limit guide by class teachers on digital games, the results regarding their performances got increased. Additionally, these results provide teachers and parents to guide their students to play games even for educational purpose accordingly. The results further analysed the differential effect on two gender groups. An important effect was detected from male students when comparing to female students. In teamwork skills female players indicates the lower results when compared to male students in both before and after playing games. And overall female student's results are lower than male student's results, except in creativity skills. In creativity skill, results show female student's results are higher than male student's results.

Furthermore, we have find out that boys are more likely to play digital game than girls. And also this paper highlights the differences which type of games boys and girls would like to play and we have describe the reason for choosing games on gender based. When take boys they incline to select games on spatial reasoning. They are most likely to play adventure type, racing games, shooting games and sports games such as like football, cricket, basketball, etc. When talking about girls they are like to select logical base or problem solving digital games and role play type digital games. In general boys are better than girls on mathematics. In this research we have emphasised that boys are not only like to play digital games that they need a guidance's based using graphics or illustration.

However, most of the games provide a substance for several types of mathematics procedures. Therefore, digital games substitute extra context to help students to think logically by playing games.

As to our research outcomes, it suggested that girls are enjoying characters of the digital games. Nevertheless lately there is an increased involvement of females using digital games. Apart from that advent of feeling of females and eager to accept the modern digital games, this improvement reflects the increasing awareness on gender specificities in digital games accordingly leads to the games that interesting and engaging female players. With the difference of the digital games for gender specific features and preferences, this enhancement could boosted further. Through gender specific version on digital games the understanding the clarifying a typically male or female concerned with digital games could be overcome towards the improvement of the games that appeal both, male and female players, could be made. Through this paper we have discussed about the framework that can be helpful to develop a digital game on both gender aspects. The understanding on gender based difference could be directing in certain procedures to be more effective improvement and the digital games concluded the understanding of one proper digital game for both genders instead of different games, and therefore using resources more effectively.

\section{References}

[1] Prensky, M. (2001). Digital natives, digital immigrants. On the Horizon, 9 (5). Retrieved February 23, 2009 
[2] Van Oers, B. (2010). Emergent mathematical thinking in the context of play. Educational Studies in Mathematics, 74, 23-37.

[3] Child Development Institute. (2012). Video games and children. Retrieved September 18, 2012

[4] Boyle, E. \& Conolly, T. (2008). Games for Learning: Does Gender Make a Difference? In T. Conolly \& M. Stansfield (Eds.), Proceedings of the 2nd European Conference on Games Based Learning (pp. 69-75).

[5] Hartmann, T. \& Klimmt, C. (2006) Gender and computer games: Exploring females' dislikes. Journal of Computer Mediated Communication, 11, 910-931. Retrieved November 4, 2008

[6] Lucas, K. \& Sherry, J. L. (2004). Sex differences in video game play: A communication based explanation. Communication Research, 31, 499-523.

[7] Agosto, D. (2004). Girls and gaming: A summary of the research with implications for practice. 31, 8-14.

[8] Graner Ray, S. (2004). Gender inclusive game design. Hingham: Charles River Media Inc.

[9] Kickmeier-Rust, M. D., Albert, D., \& Roth, R. (2007). A Methodological Approach to Address Individual Factors and Gender Differences in Adaptive eLearning. In K. Siebenhandl, M. Wagner, \& S. Zauchner (Eds.), Gender in E Learning and Educational Games: A Reader (pp. 71-84).

[10] Aikaterini Katmada, Apostolos Mavridis and Thrasyvoulos Tsiatsos "Implementing a Game for Supporting Learning in Mathematicss" The Electronic Journal of e-Learning Volume 12 Issue 3 2014, (230242)

[11] Lowrie, T., \& Diezmann, C. M. (2010). Solving graphics tasks: Gender differences in middle-school students. Learning and Instruction.
[12] Dickhäuser, O. \& Stiensmeier-Pelster, J. (2003). Gender differences in the choice of computer courses: Applying an expectancy-value model. Social Psychology of Education, 6, 173-189.

[13]Ziegler, A. \& Stoeger, H. (2004). Evaluation of an attributional retraining (modelling technique) to reduce gender differences in chemistry instruction. High Ability Studies, 15, 63-83.

[14] Werbach, K., and Hunter,D. (2012). For the Win: How Game Thinking Can Revolutionize Your Business. Wharton Digital Press.

[15] Zichermann, G., and Cunningham, C. (2011), The Gamification by Design: Implementing Game Mechanics in Web and Mobile Apps. O' Reilly Media, Cambridge. 